\title{
Success of Training Activities Depending on the Level of Social Intelligence
}

\author{
Leysan Mudarisovna Zakirova $^{1} \&$ Irina Ivanovna Frolova ${ }^{2}$ \\ ${ }^{1}$ Branch of Kazan (Volga Region) Federal University in Naberezhnye Chelny, Naberezhnye Chelny, Mira Street, \\ 68/19, Russian Federation \\ ${ }^{2}$ Institute of economics, management and law (Kazan) branch in Naberezhnye Chelny, Naberezhnye Chelny, \\ Naberezhnochelninskaya street, 31, Russian Federation \\ Correspondence: Leysan Mudarisovna Zakirova, Branch of Kazan (Volga Region) Federal University in \\ Naberezhnye Chelny, 423810, Naberezhnye Chelny, Mira Street, 68/19, Russian Federation. E-mail: \\ drzak@mail.ru
}

Received: August 15, 2014 Accepted: August 25, 2014 Online Published: November 27, 2014

doi:10.5539/ass.v10n24p112 URL: http://dx.doi.org/10.5539/ass.v10n24p112

\begin{abstract}
The problems of social interaction person with environment began to emerge to the forefront because of socio-economic changes in Russia. The analysis of the situation points to a number of factors influencing the development of socialization and social-cultural adaptation. The goal of the article is to highlight the relationship between of success of educational activities with the level of social intelligence. Social intelligence is regarded as individually-personal property of the person, which you can not only diagnose, but also to develop. We carried out a study on the relationship between the success of the training and levels of development of social intelligence of students. The study involved 140 students from various universities of Naberezhnye Chelny: 70 students of the first year students and 70-graduates. For evaluating the success of training, we used data of the last session, for the evaluation of social intelligence; we used the adaptive test of M. Sallivan and J. Guildford «Social intelligence». So we can assert that there is a connection between the success of the training activities and the level of social intelligence.
\end{abstract}

Keywords: success, social intelligence, ability, verbal communication, intellectual activity, skills, knowledge

\section{Introduction}

High school preparation is an important step in the professional development of future teachers. It is in the process of education student learns certain knowledge, skills; there is a formation and development of professional and personal qualities. As a rule, the period of professional training coincides with the period of adolescence. At that moment development of a personality intensive process of formation of the personality, this is implemented for creative potential.

Study of the phenomenon of genius is currently topical issue for various reasons. First, the society is interested in the social order for a creative person in all spheres of production. Secondly, in psychology and pedagogy insufficiently developed the concept of ontogenesis and phylogenetic of creativity. Third, the theory and practice of creativity are not yet in the process of elective symbiosis of various scientific fields. The study of creativity in all its guises is a priority in educational psychology, pedagogy, and the emerging new trend creative about the psycho-pedagogy and psychology of creative learning.

Identification and training of gifted children, pupils and students is a new task of improving the system of education. Diagnostics, development and education of gifted individuals are solved one of the problems of formation of creative potential of modern society.

The science and practice of training proved differences in creative who-ability (creativity) children and students. Differentiation of all children at each age in their creative potential is very significant-from mental retardation to high talents and General skills (Matyushkin \& Sisk, 1988).

The scientific meaning of the identification of gifted and talented is that it allows revealing the nature and psychological mechanism of creativity will provide opportunities for the use of the laws of creativity to improve the content and methods of teaching. 
Modern conceptions of giftedness distinguish different directions, and even the types of intelligence, respectively distinguishing the kinds of talent. Most psychologists consider creative potential as one of the most important, and to a certain extent, independent factors endowments. American psychologist P. Torrens identified creativity as a process generated a strong need for removal of pressure arising in a situation of uncertainty and lack of information. This process involves identifying problems, nomination and testing hypotheses about the ways of its solution, search and substantiation of decisions. The main role is played divergent (going in different directions) thinking that can lead to unexpected conclusions, unlike convergent (serial) thinking. And creativity necessarily implies intellectual development of a person is above average, since only this level can provide the basis for creative productivity. Originality is also essential structural element of genius. It expresses the level of differences, unusual, unexpected supposed solution among other standard solutions. It is defined: the transformation of the given problem in its own issue; the new one's position relation to the problem; the rejection of the standard, the «obvious» hypotheses. Originality is born of overcoming the «right», is obvious, generally accepted. According to the concept of G. Renzallee, development of talent based on the relationship of the three constructs: intelligence above the average level, creativity and commitment to the task.

Some research and practical experience in our country, as well as experience of foreign studies and the practice of early identification of gifted children and students testify to necessity of creation of a special state program providing intensive development and use of practical experience of identifying and psychological assistance to gifted students, talented children, their parents, teachers, and teachers; providing real opportunities for creative development of children and pupils at all stages of their education.

The study of talent allows for a different approach to the training and education of the Kingdom of the gifted child, to use the accumulated scientific material for psychological help him, i.e. to pass from laboratory research and awareness of the presence or absence of talent and capacity for development on the basis of and with the help of specially organized art lessons, psychological training of creative teachers, can help creative students.

Theoretic-methodological basis of the study are creative concept A.M. Matyushkin, allowing considering views about the work as a productive process of personal growth and psychological development of an individual. Approaches of V. V. Davydov, B. M. Elkonin to the mechanisms of forming reflective theoretical thinking-as the basis for creative thinking; D.B. Bogoyavlenskaya, L. M. Popov, V. I. Panov, K. M. Kamarov about creativity with other psychic phenomena; S. L. Rubinstein, V. A. Moleko, R. B. Gabdreev about the creative consciousness of the individual; M. S. Leites, V. E. Chudnovsky, Ju. Z. Gilbukh, L. C. Popova about General and special abilities of students; A. B. Brushlinski, M. I. Mahmutov, I. S. Lerner, D. B. Vilkeev about problematic training as the main means of training creatively active person.

To solve the set tasks was used set of interrelated and complementary methods. Empirical methods are based on direct experience, related to observing, questioning, testing, with the study results of operations. These methods of empirical research were supplemented by means of this level: a generalization of pedagogical experience, experiment. The analysis of psychological, pedagogical, philosophical literature, which allowed to determine the initial position of research; direct and indirect supervision of students in lectures, seminars and practical classes and class time; a graphical representation of results, mass survey (questionnaires, tests, self-esteem), the experiment. Theoretical methods: the analogy, modeling, system approach. Quantitative and qualitative analysis of experimental data is carried out on the basis of computer processing.

Taking place in Russian society socio-economic changes escalated the problem of the dehumanization of man in cooperation with the social environment. The resolution of this issue depends on the development of the ability of the active social and cultural adaptation. The assimilation of the system of standards in relations to the world, to each other is determined by the manifestation of such personality traits as social intelligence. In turn, social intelligence is an individually-personal property of the person, which is manifested in the ability to shape the attitude to you, to predict the results of their activities, understand their behavior and the behavior of others (Barabanschikov \& Ryzhkov, 2007).

The work of intelligence allows a person to build different versions of the «picture of the world». Criteria for the level of intellectual development of a personality associated with how people perceive, understand and explains reality and peculiarities of intellectual mastery of the situation are depended on it, and accordingly, behavior in this situation (Bogoyavlenskaya, 1983).

But this does not mean that the intelligence is exclusively a mechanism for adaptation to their environment. Opposite the smart people tend themselves in adaptive, because of their mental experience the specificity of the organization they observe differently, and their behavior is actually corresponds to the deep, contextual laws, joining the contradictions with the current situational requirements. 
Social intelligence-is the ability to properly understand the behavior of people. This ability is essential for effective interpersonal interaction and successful social adaptation (Teplov, 2001).

Social intelligence considers the intellect, as a manifestation of socio-useful adaptation. The detailed definition of intelligence has a long tradition. B. Shtern gave a definition of intelligence as «some general ability to the new conditions». Adaptive act-is the decision of vital tasks through intelligence-is carried out through the action of the mind (mental) equivalent of the object, through the action of the mind under the dominant role of the consciousness over the unconscious. Thanks to this solution can be carried out here and now, without external behavioral samples correctly and once: samples, check of hypotheses, are carried in the «internal action plan». In this case, «criterion of intelligent behavior is not transformation of the environment, but the opening of the environment capabilities for adaptive actions of the individual in it» (Anastazie \& Urbina, 2001).

Considering the intellect as individually-personal property of the person, we note that the content of functions is reflected double conditionality of social intelligence. Theoretical analysis of psychological and pedagogical literature can select the following functions: cognitive appraisal, communicative and cultural values, and reflective-corrective (Barysheva, 2008).

Under the personality we understand that the greatest extent determines the psychological essence of man or nature of the human psyche, interpreted differently in different approaches. You can specify only a few General provisions about the person, which are accepted by almost all authors. «One of them is that identity is something unique unity, certain integrity. Another point is the recognition of the identity of the integrating role of higher instance» (Leontev, 1975). Cementing this integrity beginning in the different approaches is defined differently. Select among them four main directions.

1) In psychological originating in Marxist philosophy, French sociological school and in some others, the personality means a social quality of the individual, «its own form of existence and development of social ties and relations» (Antsiferova, 1981); «designated involvement in social relations system as an individual, emerging in joint activities and communication» (Psychology, 1990). Although these approaches can vary considerably between first interpretations of the role of activity of the subject of social relations in the formation of his personality, inevitably acts socio-historical determination of these processes.

2) If a person be considered as the product of the inclusion of the person in public relations and joining it to the cultural norms and values, the unanswered question about the sources of the culture and social development. People not only draw from society and culture, but also makes those deposits. These contributions the larger and more significant, the worse the person. Therefore, in some philosophical and psychological directions (personalism, humanistic psychology, existentialism and others) on the first place among constituting the identity of properties put forward creative, generating the beginning, although the nature of this early interpreted in different approaches are quite different. But creating something meaningful for others, a person creates a meaningful to myself, changes himself, working his personality. You can say some paraphrasing of S. L. Rubinshtein that personality is the form of continuous man beyond himself (Smirnov, 1995).

3) Many authors in the definition of personality in the first place put her individual originality and uniqueness. (J. Guildford: the identity of the individual is the specific constellation of features). This approach is often closely intertwined with the understanding of a personality as a source of creativity, for it is the uniqueness of personality makes her a carrier of a unique experience and potential Creator of a new, original culture.

4) Kant argued that a person becomes a personality through self-awareness, enabling him to submit your «I» moral law. In the center of many psychological approaches is the study of consciousness and the «I» as a form of experiencing a man of his personality. W. James asked tradition highlight two aspects of «I»-«I $»$ knower (ego pure) and «I» knowable, which he called the experiential personality. In the last physical or material personality, social and spiritual personality is outstanding (James, 1991).

In each of the four approaches you can select multiple individual cases of understanding personality, which oppose each other in the key moments. «In psychology as many definitions of personality, as the psychologists involved in its study» (Eysenck, 1994). Therefore, it is necessary to remember that no one definition of personality cannot be considered exhaustive or at least fixing the main, essential features of such a complex and multi-faceted education, what is the personality psychology (Smirnov, 1995). Based on current research tasks and used the funds to the fore inevitably represent different aspects of the concept of personality, as in our case.

To study the extent of the creative personality manifestation allows understanding its claims, the ideological direction and value orientation. Each individual as the person is a product not only of existing relationships, but also the whole preceding history, as well as his own personal development and identity (Ananiev, 1980; 
Bozhovich, 1968; Bueva, 1978; Zeigarnik, 1982; Kon, 1989; Leontev, 1975).

Personality is lifetime holistic-structural psychological education, expressing the public the essence of a real person by A. G. Kovalev (Total psychodiagnostics, 1987.), multilevel, hierarchical self-developing system by B. G. Ananiev.

As noted by L. M. Popov, the following are the main provisions in the consideration of problems of development of the person as the subject of self-development.

First, if the person is considered as a certain system, the main task here is to identify the «components» of this person and ways of its organization.

Second, the consideration of psychic phenomena is abstract, which allows you to cover only one side of it. Therefore, to understand at once studied the phenomenon in General is impossible. Attempts to disseminate the findings obtained during the study, for everything else, usually, to succeed, not lead.

Thirdly, the system of psychic phenomena-layered and is built hierarchically. It includes a number of subsystems. There are three main inextricably interrelated processes: cognitive, regulatory, and communicative. In turn, each of them can be divided further. The most studied of these subsystems is cognitive.

Fourth, description, analysis of the properties of the person you want to lead based on the multiplicity of relations of man as individual, individuals, entity. Classification of property rights must be multidimensional.

Fifth, the determination is also multi-faceted, multi-level, and multi-dimensional. While often the diversity of psychic phenomena tries to explain some single universal determination.

Sixth, the phenomenon should be considered in the development. Integrity is formed and destroyed in the course of development. Mental occurs exists and changes in the actual development of the system, the property of which he is.

In the course of the development there is a change of determinants, some of which are leading (Popov et al., 2008).

Most psychologically important component of the personality and the subject is, firstly, intelligence and its components. Intelligence is the ability and the quality of the living system of orientation in time and space. The goal is survival, adaptation, meaningful transformation of the surrounding space, interpersonal and social relations of production, and self-transformation himself.

Second, the ability of a person to be indifferent to the fact that he himself does not indifferent to the many influences that it is (to act with yourself and with others). In other words, to what determines all the process of its activity, which is associated with the peculiarities of his emotional world.

So, you can be identified in the structure of man as a personality, subject of education two complexes: the intellectual (space-time) and your own personal (determinate) (Popov et al., 2008).

Intellectual complex is a system-structural organization, its involvement in the multidimensional processes of human interaction with the world and with him, as well as technologies (methods, techniques) of this interaction.

Actually personality complex as if frames intellectual complex psyche and is an influence that has the strongest influence on the behavior of the subject. This influence depends on the attitude to you, to others and gives the processes of interaction of the individual identity (Popov et al., 2008).

On the basis of the structure of personality in the course of our work was the dynamics and development of talents of a future teacher in the conditions of professional training at the University.

\section{Materials and Methods}

To assess social intelligence we used the adapted test of M. Sallivina and G. Guildford «Social intelligence». Research methodology includes 4 subtests. Three subtests built on non-verbal stimulus material and one verbal. These sub tests diagnose four abilities in the structure of social intelligence: knowledge classes, systems, transformations and results behavior.

The knowledge of the classes of conduct-the ability to recognize common properties in some thread expressive or situational information about the behavior.

The knowledge systems of conduct-is the ability to understand the logic of the development of a situation of human interaction, meaning their behavior in these situations.

The knowledge of the conversion of conduct is the ability to understand change the value of similar behavior in different situations. 
The knowledge of the results of conduct-the ability to foresee the consequences of behavior, based on the available information.

Each subtest contains 12-15 jobs. The execution time of the sub tests is limited. Questionnaire forms are processed using a special key. The results are calculated for each subtest separately and around overall. Results for individual sub tests reflect the level of one (or several) abilities factor of cognition behavior. The result on the test reflects the General level of development of social intelligence. The General meaning of standard points on separate sub tests can be determined as follows: 1-low capacity for learning behavior; 2-the capacity for learning behavior below average; 3-average capability to the knowledge of the behavior (medium selective norm); 4-the ability to know the behavior above average; 5-high capacity for learning behavior. The General level of development of social intelligence (integral factor of cognition behavior) is determined on the basis of composite scores as follows: 1-low social intelligence; 2 -social intelligence is below average; 3 -average social intelligence; 4-social intelligence above the average; 5-high social intelligence.

We carried out a study on the relationship between the success of the training and levels of development of social intelligence of students. The study involved 140 students from various universities of Naberezhnye Chelny: 70 students of the first year students and 70-graduates. For evaluating the success of training, we used data of the last session, for the evaluation of social intelligence; we used the adaptive test of M. Sallivan and J. Guildford «Social intelligence».

\section{Results}

The complex of interrelated and complementary methods of research was used for solving the tasks. The analysis of psychological, pedagogical, philosophical literature are hold, its allowed defining the starting positions of the research; direct and indirect supervision of the students in the classroom and in extracurricular time; a graphical representation of results, mass survey (questionnaires, tests) (Derkach, 1996; Zakirova \& Shulaeva, 2013). Quantitative and qualitative analysis of experimental data was performed on the basis of computer processing.

A high level of overall intellectual development, in particular perceptions, views, memory, thinking, attention, level of certain circle of logical operations and etc. is required for successful training. Students should be characterized by breadth of cognitive interests, eggheadism, rich vocabulary, and be able to properly use it, exactly match specific and abstract concepts and have general developed of abstract thinking. Though while taking the lowest indicators of the level of overall intellectual development, it is possible to compensate by increasing the motivation and efficiency, diligence, thoroughness and accuracy in training activities.

There are dynamic changes in the level of reliability of differences of 0.01 in the process of training activities. In terms of sexual dimorphism, we note that the IQ of boys and girls also increases and has dynamic changes towards increase and not statistically different from each other indicators with a confidence level equal to 0.01 . The percentage is the following: $4.67 \%$ of students in the first year of training with high IQ, $17.33 \%$-above average, $48 \%$-average, $30 \%$ lower than average; graduates- $5.33 \%, 22 \%, 53.34 \%, 19.33 \%$ respectively.

Thus, the development of the intellectual characteristics of personality in the process of learning is traced. And the most important is to change the quantitative composition of secondary (higher) and lower secondary (lower) level of development of general abilities (probability of error of 0.01 ). So the first year students have the direct connection between these indices where $r=0.92$ at a significance level of 0.001 and graduates it is equal to 0.66 , and corresponds to the level of significance of 0.001 .

The methodology of M. Salliven and J. Guildford «Social intelligence» has allowed us to measure the overall level of social intelligence. The structure of social intelligence is: the ability to predict the consequences of conduct; the ability to understand the logic of the development of complex situations of interpersonal development; the ability to adequately reflect the verbal and non-verbal expression of conduct.

The results of research of a level of social intelligence are given in Table 1.

Table 1. Indicators of the level of social intelligence

\begin{tabular}{lll}
\hline & The level of social intelligence & \\
& boys & girls \\
\hline The first year students & 2,8 & 2,5 \\
Graduating students & 3,4 & 3,8 \\
\hline
\end{tabular}


As we can see from the Table 1, the level of student's social intellect is average rate, i.e. graduates can retrieve information about the behavior of people, to understand the language of non-verbal communication.

In addition, the level of social intellect increases in the learning process. You can see the dynamic changes in the direction of increasing the level of social intelligence of girls and boys. So the boys' indicators of social intelligence are increased by 0.6 points and have statistical validity of $\mathrm{p} \leq 0.05$. The girls' level of social intelligence is also characterized by dynamic changes towards increase (1.3 points) and statistically significant ( $\mathrm{p}$ $\leq 0.05)$.

Thus, we can say that the students towards the end of the training are able to obtain information about the behavior of people, to understand the language of non-verbal communication, to make fast and accurate judgments about people, successfully predict their reaction in specified circumstances, be wide awake in relations with others, that contributes to their successful social adaptation. Students with social intelligence above the average level, as a rule, are successful communicators. They have rapport, openness, tact, kindness and cordiality, the trend towards psychological closeness of the communication. Social intelligence connected with an interest in social problems, the presence needs to affect others and is often combined with the developed organizational skills. Students with a developed social intelligence usually have expressed interest in learning about themselves and a developed ability to reflection. Students with above average social intelligence are usually easy to get in the team, help to maintain optimal psychological climate, show more interest, wits and ingenuity.

\section{Discussion}

In connection with the fact that social intelligence refers to the ability to foresee the consequences of conduct and logic of the development of complex situations, it can be assumed that the level of development of social intelligence will affect the level of the intellectual development in general.

Analyzing the correlation between the success of the training activities and the level of social intelligence we can suggest that such relationship is very strong (Table 2).

Table 2. The results of correlation analysis between the indicators of the level of intellect and social intelligence (the first year of study)

\begin{tabular}{lllll}
\hline \multirow{2}{*}{ The level of social intelligence } & \multicolumn{4}{l}{ The level of intelligence (by G. Eysenck) } \\
& High & Above average & Average & Below average \\
\hline High & $0.48^{* *}$ & 0.35 & 0.27 & 0.14 \\
Above average & 0.29 & $0.36^{*}$ & 0.34 & 0.22 \\
Average & 0.27 & $0.39^{*}$ & $0.41^{*}$ & 0.27 \\
Below average & 0.15 & 0.28 & 0.32 & 0.3 \\
\hline
\end{tabular}

Note: ${ }^{*}$-p $\leq 0.05 ; * *-p \leq 0.01$

The analysis of Table 2 shows that there is a relationship between the level of social intelligence and the General level of intelligence, i.e. than higher intellectual level of the individual, the higher the level of social intellect. For example, the high level of intelligence correlates with a high level of social intelligence $(r=0.48 p \leq 0.01)$. The relationship between the indicators above-average intelligence and levels of social intelligence of above average and average $(r=0.36, r=0.39$, respectively, $\mathrm{p} \leq 0.05)$ are expressed slightly weaker.

So, developing the intellect of a person, we can raise the level of social intellect.

The results of correlation analysis between the studied indicators for students of last year of study are presented in the Table 3.

The analysis of Table 3 also confirms the assumption that there is a relationship between the level of social intelligence and the general level of intelligence. The hypothesis that the higher intellectual level of the individual, the higher the level of social intelligence is confirmed. So a high level of intelligence correlates with a high level of social intelligence $(r=0.53 \mathrm{p} \leq 0.01)$ and with above-average level $(\mathrm{r}=0.38, \mathrm{p} \leq 0.05)$. A statistically significant relationship between the indicators above-average intelligence and levels of social intelligence is above average $r=0.48 p \leq 0.01$ and average level of $r=0.38 p \leq 0.05$. 
Table 3. The results of correlation analysis between the indicators of the level of intellect and social intelligence (last year of study)

\begin{tabular}{lllll}
\hline \multirow{2}{*}{ The level of social intelligence } & \multicolumn{4}{l}{ The level of intelligence (by G. Eysenck) } \\
& High & Above average & Average & Below average \\
\hline High & $0.53^{* *}$ & 0.32 & 0.25 & 0.24 \\
Above average & $0.38^{*}$ & $0.48^{* *}$ & 0.29 & 0.29 \\
Average & 0.31 & $0.38^{*}$ & $0.49^{* *}$ & 0.22 \\
Below average & 0.19 & 0.18 & 0.32 & 0.17 \\
\hline
\end{tabular}

Note:*-p $\leq 0.05 ;{ }^{* *}$-p $\leq 0.01$

\section{Conclusion}

So we can assert that there is a connection between the success of the training activities and the level of social intelligence.

The development of social intelligence allows sharing information actively. It allows you to highlight important information, it is especially important, as people not only to share knowledge, but also strive to develop common sense. It's possible only under the condition that the information not only adopted, but also understood and comprehended. Communication impact as a result of the exchange of information is possible only when the people making the information. And the person taking it, have the same or similar codification system and recodification. This is especially important because the communicator and the recipient in the communication process constantly change their places. Any exchange of information between them is possible only if the characters, and most importantly, their assigned values known to all participants of the communication process. Only the adoption of a uniform system of values provides the opportunity for partners to understand each other. These opportunities can be developed and improved through social intelligence.

Knowledge of the specific features and regularities of the process of formation of social intelligence gives the possibility to adjust the learning process, directing it to the formation of the integrity of the internal structure of the person, the development of self-consciousness, needs, and abilities.

\section{References}

Ananiev, B. G. (1980). Man as a subject of education: Selected psychological works (p. 287). Moscow: Pedagogy.

Anastazie, A., \& Urbina, S. (2001). Psychological Testing (7th ed., p. 688). St. Petersburg: Piter.

Antsiferova, L. I. (1981). To the psychology of personality as a developing system//Psychology of formation and development of personality (pp. 3-19). Published by Moscow.

Barabanschikov, T. A., \& Ryzhkov, A. N. (2007). In A. F. Anufriev (Ed.), Psychological methods of studying of the person: Workshop.

Barysheva. (2008). Creativity: Theory, diagnostics, technology: Reference dictionary for specialists working in the areas of education, innovations and humanitarian technologies in the social sphere. Spb.

Bodalev, A. A. (1987). Total psycho-diagnostics (p. 304). Moscow: MSU.

Bogoyavlenskaya, D. B. (1983). Intellectual activity as a psychological aspect of creativity studies. In Y. A. Ponomareva (Ed.), Studying problems in the psychology of creativity (p. 191). Published by Moscow: Nauka.

Bozhovich, L. I. (1968). Identity and its formation in childhood (p. 464). Moscow: Education.

Bueva, L. P. (1978). Person: Activities and socializing (p. 216). Moscow: Thought.

Derkach, A. A. (Ed.) (1996). The workbook of a practical psychologist: Technology of effective professional activity (a manual for specialists working with the staff) (p. 400). Moscow: Red square.

Eysenck, H. J. (1994). In R. J. Sternberg, \& P. Ruzgis (Eds.), Personality and intelligence: Psychometric and experimental approaches. New York: Cambridge University Press.

James, W. (1991). Psychology (p. 368). Moscow: Longman. 
Kon, I. S. (1989). In A. V. Petrovsky (Ed.), Socialization and education of young people: A New pedagogical thinking (p. 278). Moscow: Longman.

Leontev, A. N. (1975). The activity. Consciousness. The personality (p. 304). Moscow: Political publishing house.

Matyushkin, A. M., \& Sisk, P. A. (1988). Gifted and talented children. Journal Questions of psychology, 4, 88-97.

Petrovsky, A. V. (1998). Psychology (p. 512). Rostov-on-don, PHOENIX.

Popov, L. M., Golubeva, O., \& Ustin, P. N. (2008). Good and evil in the ethical personality psychology (p. 240). Moscow: Institute of Psychology RAS.

Smirnov, S. D. (1995). Pedagogics and psychology of higher education: From activity to the identity: Teaching aid for students of the faculties and institutes of advanced training of University teachers and graduate students (p. 271). Moscow: Aspect Press.

Teplov, B. M. (2001). Selected works (Vol. 1, p. 648). Moscow: Education.

Zakirova, L. M., \& Shulaeva, M. V. (2013). Psychological conditions of creative development of personality (p. 245). Polygraph center Guzel.

Zeigarnik, B. V. (1982). Theory of personality in foreign psychology. Moscow: Moscow state University.

\section{Copyrights}

Copyright for this article is retained by the author(s), with first publication rights granted to the journal.

This is an open-access article distributed under the terms and conditions of the Creative Commons Attribution license (http://creativecommons.org/licenses/by/3.0/). 